Grand Valley State University

ScholarWorks@GVSU

2000

\title{
Asymmetrical Social Influence in Freely Interacting Groups Discussing the Death Penalty: A Shared Representations Interpretation
}

\author{
Christine M. Smith \\ Grand Valley State University, smithc@gvsu.edu \\ Amanda Dykema-Engblade \\ Loyola University Chicago \\ Angela Walker \\ University of Connecticut \\ Tammi S. Niven \\ University of Nebraska \\ Thomas McGough \\ Grand Valley State University
}

Follow this and additional works at: https://scholarworks.gvsu.edu/psy_articles

Part of the Psychology Commons

\section{ScholarWorks Citation}

Smith, Christine M.; Dykema-Engblade, Amanda; Walker, Angela; Niven, Tammi S.; and McGough, Thomas, "Asymmetrical Social Influence in Freely Interacting Groups Discussing the Death Penalty: A Shared Representations Interpretation" (2000). Peer Reviewed Articles. 52.

https://scholarworks.gvsu.edu/psy_articles/52

This Article is brought to you for free and open access by the Psychology Department at ScholarWorks@GVSU. It has been accepted for inclusion in Peer Reviewed Articles by an authorized administrator of ScholarWorks@GVSU. For more information, please contact scholarworks@gvsu.edu. 


\title{
Asymmetrical Social Influence in Freely Interacting $G$ roups Discussing the Death Penalty: A Shared Representations Interpretation
}

\author{
Christine M. Smith \\ Grand Valley State University
}

\section{Amanda Dykema-E ngblade \\ L oyola University}

\section{Angela Walker}

University of Connecticut

\section{Tammi S. N iven}

University of N ebraska

\section{Thomas McG ough}

Grand Valley State University

\begin{abstract}
Past research has shown that minorities arguing in favor of the majority opinion within a given population (i.e. the 'Zeitgeist') are more powerful sources of social influence than minorities arguing against the normative population opinion (i.e. Clark \& M aass, 1988a and b; Paicheler, 1977). We studied the Zeitgeist effect within the context of freely interacting groups discussing the death penalty. In direct contrast to past research, minorities arguing against the death penalty Zeitgeist were more powerful sources of social influence than those arguing in favor of it. Analyses of conversation content and thought-listing data suggest that minorities arguing against the death penalty may have been more influential because they were appealing to a superordinate shared belief system within their respective groups.
\end{abstract}

keywords minority influence, shared representations, Zeitgeist effects

Wh en Moscovici and his colleagues published their classic experiment regarding minority influence in 1969, the functionalist approach was the prevailing paradigm utilized in the study of social influence (M oscovici, Lage, \& Naffrechoux, 1969). The central assumption of the functionalist approach was that social influence is asymmetrical, or in other words, that majority members were the source of social influence but never the possible targets of minority influence

\section{Author's note \\ Address correspondence to Christine M. Smith, Department of Psychology, Grand Valley State University, Allendale, MI 49401, USA [email: SmithC@GVSU.edu]}


(Festinger, 1950, 1954). Moscovici (1976) was highly critical of this particular approach, largely because it precluded the possibility of a successful minority social movement. In addition to his empirical work, Moscovici had ample historical evidence supporting his argument that minorities were powerful sources of influence who inspired innovative social change.

After almost 30 years of research on minority influence, the question is no longer whether or not minorities are influential, but rather, under what conditions opinion minorities are most influential. Although this question has been addressed in numerous empirical investigations ( see Levine \& Russo, 1987; M aass \& Clark, 1984; Nemeth, 1986; and Wood, Lundgren, Ouellette, Busceme, \& Blackstone, 1994 for excellent reviews of this research), a particularly interesting line of research has involved comparing numerical minorities arguing in favor of and against the same attitudinal issue (Clark, 1988; Kruglanski \& Mackie, 1990; Maass, Clark, \& Haberkorn, 1982). A critical variable in these studies seems to be whether the minority is arguing for or against a position that isprevalent in the general population (i.e. the 'Zeitgeist'). The majority of these studies have revealed strong asymmetries in social influence patterns, with minorities arguing in favor of the Zeitgeist being more potent sources of social influence than those arguing against the spirit of the times'. In two experimental investigations Paicheler exposed participants to either a minority source of influence arguing in favor of women's rights (pro-Zeitgeist) or against women's rights (anti-Zeitgeist). In each study she found that the minority arguing in favor of the Zeitgeist exerted more social influence than the minority arguing against women's rights (Paicheler, 1976, 1977). Similarly, Clark and Maass found consistent asymmetries in the social influence patterns of minorities arguing in favor of and against gay rights and abortion (1988a, 1988b, 1990). Again, minorities arguing in favor of the current 'majority opinion' in the general population were more influential than those who argued against the majority position.

It is important to note that in both the
Paicheler (1976, 1977) and Clark and Maass (1988a, 1988b, 1990) studies the Zeitgeist was operationally defined as the predominant or majority opinion within a defined population (i.e. majority opinion). The Zeitgeist may also be construed as a minority trend in a population whose strength of momentum suggests that it will ultimately represent majority opinion. That is, the former definition of the Zeitgeist represents that which is already accepted by the majority and the latter definition of the Zeitgeist represents that which will become majority opinion. In order to use the 'minority movement with sufficient strength of momentum' definition of Zeitgeist, one would have to predict in advance the success of a particular minority movement. Given that it is historically impossible to make precise a priori predictions regarding the success of a given minority movement, it makes sense that empirical investigations of the Zeitgeist effect have relied exclusively on the 'current majority opinion' definition of Zeitgeist.

Several explanations for the asymmetrical social influence patterns in Zeitgeist studies have been offered. Clark (1990) argued that minority arguments in line with the Zeitgeist may be perceived as more valid than arguments that run counter to the spirit of the times because of the implied social support for the position being argued. In other words, for issues where an objectively cor rect position cannot be determined (as is the case with women's rights, gay rights, abortion, and the numerous other judgmental issues used in the research showing Zeitgeist effects) social support may be used to gauge the validity of a given position. Clark argued that a minority faction can demonstrate social support for its position in one of two ways. First, it may do so by arguing in favor of the current Zeitgeist. Second, social support for the minority position can be demonstrated through the movement of majority members to the minority position. The latter method was supported in Clark's 1990 investigation that utilized a condensed version of the play Twelve Angry $M$ en (Rose, 1954). In this experiment, participants were exposed to jury deliberation transcripts where a minority juror argued in favor of 
acquittal. Minority influence was greatly enhanced when the transcript included the depiction of several majority faction defectors. The same experiment revealed that the minority's ability to successfully refute majority members' arguments also greatly enhanced minority influence potency. Clark (1990) argued that his findings provided a framework for understanding the asymmetry problem in minority influence.

Clark's explanation for the consistent asymmetries found in the minority influence literature is not without its critics. For example, Perez, Papastamou, and Mugny (1995) asserted that Clark's explanation suggests that minority influence can be understood within the classic conformity/ dependence framework and they correctly argue that much of the minority influence literature is inconsistent with this notion ( see Clark, 1995 for a response to this criticism).

Conversely, Mugny and Perez (1991) suggest that one of the many ways in which minorities can be influential is when they link their arguments to a common normative principle that is shared by both the majority and the minority. This explanation, relative to Clark's, broadens considerably the conditions under which minorities are likely to exert social influence in that it is not necessar $y$ for the minority to argue in favor of the position held by the majority of a population on the specific issue at hand. That is, minorities can validate their counternormative position by linking their arguments to some shared superordinate belief or value system. For example, consistent with Mugny and Perez's reasoning, a persuasive message against the consumption of animal products (a minority position in the United States) would be more influential when it pointed out how the consumption of animal products was incongruent with a general respect for all living things than when the superordinate socially shared belief (respect for life) was not mentioned.

A conceptually similar principle applicable to both minority and majority influence has been put forth and empirically supported by Tindale and his colleagues (Smith, Tindale, \& Anderson, in press; Tindale, Smith, Thomas, Filkins, \& Sheffey, 1996). A 'shared representation' is any task or situation-relevant concept, norm, perspective, or cognitive process that is shared by most or all of the group members. The presence of a shared representation results in asymmetrical influence patterns favoring a particular decision alternative (Smith, Tindale, \& Steiner, 1998; Tindale, Sheffey, \& Filkins, 1990; Tindale, Filkins, Thomas, \& Smith, 1993). That is, both minorities and majorities favoring the alternative consistent with the shared representation exert greater influence than factions favoring alternatives inconsistent with the shared representation. For example, the 'reasonable doubt criterion' operates as a shared representation within the context of jur y deliberations. The large body of mock jury research has revealed strong asymmetries in the social influence patterns with those favoring acquittal (which is consistent with the reasonable doubt criterion) being more influential than those arguing in favor of conviction (Davis, Kerr, Stasser, Meek, \& Holt, 1977; Kerr \& MacCoun, 1985; Nemeth, 1977; Tindale, Davis, Vollrath, Nagao, \& H insz, 1990). Tindale and his colleagues have found direct minority influence on both intellective tasks (e.g. those with a demonstrably correct response) and judgmental tasks (e.g. those for which there is not a demonstrably correct response) when a shared representation is present and the minority's arguments are consistent with the shared belief/ value system.

The literature on opinion deviance in groups suggests that minority sources of influence are more likely to be rejected, and therefore less likely to be influential, when they impede group locomotion (Levine, 1980). This effect is exacerbated when group members are highly interdependent (Berkowitz \& H oward, 1959) and when the minority is perceived as being responsible for the group's failure (Jones $\&$ deCharms, 1957; Miller \& Anderson, 1979). In a series of studies Miller and his colleagues explored the effects of several different group decision making rules (e.g. majority, unanimity) on group members' acceptance of opinion deviates (Miller \& Anderson, 1979; Miller, Jackson, Mueller, \& Schersching, 1987). In each study Miller found that minorities in unanimous 
decision making groups, because they could easily impede group locomotion, were evaluated much more unfavorably than minorities in groups where members operated under a majority decision rule. This research suggests that minorities may be evaluated more positively and may be more likely to influence others when they do not impede group goal attainment (see also Smith, Tindale, \& Dugoni, 1996). On the other hand, it is unlikely that being perceived negatively necessarily precludes the ability to influence. For example, Nemeth (1977) found more social influence in groups required to reach unanimous as opposed to a majority supported verdicts in a jury decision making study. In juries where a unanimous verdict was required minority factions often prevailed, but only when they were arguing in favor of acquittal. Nemeth's work suggests that certain contexts (e.g. groups working under a unanimous decision rule) may empower minority factions to insist that their viewpoint be heard and that the final group product reflects their position. In addition, it suggests that the ease with which a particular position is defended affects minority influence. As stated earlier, the 'reasonable doubt criterion' makes the acquittal position much easier to defend.

Although minority and majority influence processes are always conceptualized as interactive, they are rarely studied together in the context of freely interacting groups (but see Smith et al., 1996; Tindale et al., 1990a). That is, confederates typically play the role of minority sources of influence within a group, or perhaps more commonly, individual subjects are provided with bogus feed back from ostensible fellow minority participants. Even more surprisingly, very few empirical investigations of the Zeitgeist effect have focused upon the content of the minority's arguments. Without such analyses, it is difficult, if not impossible, to assess the validity of any of the explanations for the Zeitgeist effects found in the literature. That is, in order to assess whether successful minorities are appealing to a superordinate belief system or a shared representation, one must document the specific arguments put forth by the minority.

\section{O verview of the present study}

In the present study we attempted to increase the level of ecological validity beyond that typically found in studies exploring Zeitgeist effects in minority influence. We did so by exploring the social influence processes within freely interacting groups discussing the death penalty. We chose this particular issue because both pilot data collected at Grand Valley State U niversity and national opinion polls in the U nited States indicate that there is a strong majority in favor of capital punishment. ${ }^{1}$ There also happens to be an overarching shared belief/ value system within our participant population that appears to be relevant to the death penalty issue. The majority of students at Grand Valley State U niversity identify very strongly with the Christian religion. If minorities arguing against the death penalty use religion to justify their position, majority members may perceive their arguments as valid and thus highly influential. That is, minority members could validate their counternormative position by making salient the group members' strongly shared Christian values and identities. Therefore, in direct contrast to past research, minorities arguing against the death penalty Zeitgeist may be more influential than those arguing in favor of it.

Roughly half of the groups in the present study were required to reach consensus regarding their opinion on the death penalty. ${ }^{2}$ The research on opinion deviance within groupssuggests that minority members within consensus seeking groups are more likely to be viewed unfavorably relative to minority members in discussion contexts. If being perceived unfavorably adversely affects the ability to influence, minority members in consensus seeking contexts are expected to be less influential than minority members in discussion contexts. On the other hand, Nemeth's (1977) work points to the importance of context in predicting minority influence potency. Minority members in consensus seeking contexts may be more influential relative to those in discussion groups because the group decision making norms in consensus seeking groups encourage the thoughtful consideration of every person's view. In addition, 
the anti-death penalty position may be easier to defend if religious justification is used.

\section{Method}

\section{Participants}

Two hundred and twenty introductor y psychology students participated as either individuals ( $N=35$ ) or asmembers of five-person discussion groups ( $\mathrm{N}=185,37$ groups). All participants received course credit for their participation and were randomly assigned to experimental conditions.

\section{Design}

Five-person groups with both single and supported minorities were studied. More specifically, groups with single ( $N=8$ groups) and supported $(N=13)$ minorities arguing against the death penalty (against the Zeitgeist) were compared to groups with single ( $\mathrm{N}=5$ groups) and supported ( $N=11$ groups) minorities arguing in favor of the death penalty (proZeitgeist). Twenty groups were asked to reach consensus( $\mathrm{N}=13$ supported minority groups and $\mathrm{N}=7$ single minority groups) and 17 of the groups simply discussed the issue without making a collective judgment regarding the death penalty ( $\mathrm{N}=11$ supported minority groups and $\mathrm{N}=6$ single minority groups). In addition, several dependent measures designed to assess discussion quality, group members' perceptions of one another, and cognitive processes were collected.

\section{M aterials and procedures}

The experiment was introduced to participants as one that explored how people thought about important social issues as individuals and as members of discussion groups. Each group participant was seated around a large table and told that she/ he would take part in a group discussion that would be audiotaped. First, participants responded to a pretest comprised of two questions regarding the death penalty. The first question required the participants to respond categorically (in favor/ against) to the issue, and the second question required them to respond to a 21-point bipolar scale (ranging from 50 to
-50 , in intervals of 5 , with a mid-point of 0 ) indicating the degree to which they were in favor of/ against the death penalty.

After responding to the pretest measure, participants were asked to discuss the death penalty with their fellow group members. Before leaving the room the experimenter told the groups that it was very important that ever y group member participate in the discussion and to encourage this, she/ he suggested that the group begin its conversation with each member stating her/ his position along with one of the reasons they held their position. All group discussions were audiotaped in order to keep track of the thoughts brought forth during discussion. Individuals who were members of consensus seeking groups were given a group decision sheet on which they were asked to record their final group position regarding the death penalty. Groups were required to respond both to the dichotomous question (in favor/ against) and to the 21-point bipolar scale. Although they were not informed at the outset that they were operating under time constraints, consensus seeking groups discussed the issue until a decision was reached or 25 minutes had passed. Each nonconsensus seeking group was asked to discuss the issue until the experimenter returned to the room. In these groups consensus was not required or requested. Each nonconsensus group was matched to a consensus seeking group with respect to discussion duration. At the end of the discussion period the experimenter returned to the room and informed the participants that the group discussion part of the experiment was over. Participants were then given the same attitude measure and asked to state once again their position regarding the death penalty and to respond to the 21-point bipolar scale.

At this point participants were asked to work independently and to list all of their thoughts regarding the death penalty. They were given two sheets of paper each divided into two columns labeled 'arguments' and 'counterarguments'. They were asked to list every thought that came to their mind. They were given 10 minutes to do so.

Finally, group members were asked to respond to several questions designed to assess 
Table 1. Raw and relative frequencies of change in position for both minority and majority members ( relative frequencies are in parentheses)

\begin{tabular}{|c|c|c|c|c|}
\hline & \multicolumn{2}{|c|}{ Consensus } & \multicolumn{2}{|c|}{ Nonconsensus } \\
\hline & Majority & Minority & Majority & Minority \\
\hline O riginally against death penalty & $\begin{array}{c}2 \\
(6.7 \%)\end{array}$ & $\begin{array}{c}3 \\
(18.8 \%)\end{array}$ & $\begin{array}{c}1 \\
(5.0 \%)\end{array}$ & $\begin{array}{c}5 \\
(26.3 \%)\end{array}$ \\
\hline Originally in favor of death penalty & $\begin{array}{c}1 \\
(2.9 \%)\end{array}$ & $\begin{array}{c}6 \\
(40 \%)\end{array}$ & 0 & 0 \\
\hline
\end{tabular}

the quality of their discussion (e.g. 'our discussion was very thorough', 'I learned newinformation about the death penalty today', 'it was easy to defend my side of the argument') and to also evaluate each member of their group along several dimensions (e.g. 'this group member seemed very intelligent', 'this group member seems rigid in their opinion regarding the death penalty', 'this group member made our discussion more stimulating'). Each question was followed by a 9-point scale with 'agree' and 'disagree' as the scale anchors. Upon completion of thisfinal task, group participants were debriefed and thanked for their participation.

Individual participants only responded to the death penalty attitude pretest and listed their thoughts regarding the death penalty. They were given 10 minutes to list their thoughts. After doing so, they were debriefed and thanked for their participation.

\section{Results}

\section{Changes in dichotomous (in favor/ against) responses}

Participants' pretest and posttest responses to the dichotomous question (in favor/ against the death penalty) were used to create a variable that reflected whether or not the participant had changed her/ his position regarding the death penalty during the course of the experiment. This variable was submitted to a 2 (minority member vs. majority member) $\times 2$ (consensus vs. discussion) $\times 2$ (against vs. in favor of the death penalty) log-linear crossclassification analysis. T able 1 shows the raw and relative frequencies of individuals who changed their position during the course of the experimental session. The model provided an adequate fit of the observed data $(p>.20)$ after all three main effects and the consensus by position and position by status (minority vs. majority) two-way interactions were entered $\left(\chi^{2}(1, N=\right.$ $180)=0.250, p=.88$ ). T wo effects were found to influence the fit of the model. First, those who were minority members within their group changed their position more frequently (23\%) than those who were majority members within their group $(3 \%)\left(\chi^{2}(1, N=180)=16.76, p>\right.$ $.01)$. There was also a significant consensus condition by death penalty position interaction $\left(\chi^{2}(1, N=180)=7.17, p<.01\right)$. In the consensus condition, those who were against the death penalty changed their position almost as frequently as those who were in favor of the death penalty ( $10 \%$ and $14 \%$ respectively). In the nonconsensus condition there was alarge difference between the rate at which those who were against the death penalty changed their position $(15 \%)$ and those who were in favor of the issue (0).

\section{Attitude change on the continuous variable}

Mean pretest death penalty attitude scores for majority and minority members within groups are presented in Table 2. A 2 (member of a group with a single vs. supported minority member) $\times 2$ (majority vs. minority member) $\times$ 2 (consensus vs. nonconsensus seeking group) $\times 2$ (participant in favor of vs. against the Zeitgeist) analysis of variance was performed on the pretest death penalty attitude scores. There were no significant main or interaction effects across the 16 cells. 
Table 2. Mean pretest scores, standard deviations, and cell sizes for minority and majority members for each condition within the experimental design

\begin{tabular}{lcccc}
\hline & \multicolumn{2}{c}{ Consensus } & \multicolumn{2}{c}{ Nonconsensus } \\
& $\begin{array}{c}\text { Single } \\
\text { minority }\end{array}$ & $\begin{array}{c}\text { Supported } \\
\text { minority }\end{array}$ & $\begin{array}{c}\text { Single } \\
\text { minority }\end{array}$ & $\begin{array}{c}\text { Supported } \\
\text { minority }\end{array}$ \\
\hline $\begin{array}{l}\text { Minority in favor of the Zeitgeist } \\
\text { Majority members }\end{array}$ & 28.12 & 30.83 & 27.18 & 30.00 \\
& $(11.67)$ & $(11.91)$ & $(12.24)$ & $(12.46)$ \\
Minority members & 16 & 18 & 16 & 20 \\
& 28.75 & 25.83 & 23.33 & 27.33 \\
Minority against the Zeitgeist & $(16.52)$ & $(14.89)$ & $(7.63)$ & $(14.49)$ \\
Majority members & 4 & 12 & 3 & 15 \\
& 22.00 & 30.27 & 23.75 & 22.91 \\
Minority members & $(14.18)$ & $(15.85)$ & $(6.94)$ & $(11.76)$ \\
& 10 & 18 & 8 & 12 \\
& 35.00 & 31.66 & 25.00 & 27.14 \\
& $(25.98)$ & $(11.74)$ & $(17.19)$ & $(12.86)$ \\
\hline
\end{tabular}

In order to assess attitude change in majority members exposed to minorities arguing against and in favor of the death penalty Zeitgeist, change scores were computed for each individual. Change scores were computed differently for majority members in favor of and against the death penalty because of the nature of the bipolar scale used. For majority members who were in favor of the death penalty ( and used the positive end of the scale) change scores were computed by subtracting posttest attitude scores from pretest attitude scores. For majority members who were opposed to the death penalty (and used the negative end of the scale) change scores were computed by subtracting pretest attitude scores from posttest attitude scores. Thus, in all instances, negative attitude change reflects movement toward the minority position and positive attitude change reflects movement away from the minority position. A 2 (minority in favor of/ against the death penalty) $\times 2$ (consensus/ nonconsensus seeking group) $\times 2$ (single vs. supported minority source of influence) analysis of variance was performed on the attitude change scores of the majority members within groups. There wasa main effect for position taken by the minority $(F(1,116)=$
5.14, $p=.02$ ). Majority members who were exposed to minorities arguing against the Zeitgeist changed more toward the minority position ( $M=-3.33$ ) than did majority members who were exposed to minorities arguing in favor of the Zeitgeist ( $M=1.66$ ). There was no main effect for consensus condition. There was a marginal main effect for single versus supported minority condition $(F(1,116)=2.17, p=.14)$. Majority members who were exposed to single minorities changed less ( $M=0.400$ ) than those exposed to supported minorities ( $M=-2.53$ ). There was a two-way interaction between position taken by the minority and consensus condition $(F(1,116)=4.66, p<.05)$. Majority members exposed to minorities arguing against the death penalty in consensus seeking groups shifted their opinions toward the minority position ( $M=-6.03$ ), whereas majority members exposed to minorities arguing in favor of the death penalty became more extreme in their anti-death penalty attitudes ( $M=3.21$ ). Majority members in nonconsensus seeking groups shifted ver yslightly toward the minority opinion both when the minority was arguing against the death penalty ( $M=-0.71$ ) and when the minority was arguing in favor of the death penalty 
$(M=-0.50)$. Finally, there was a marginally significant interaction between consensus condition and whether or not the majority member was exposed to a single or supported minority member $(F(1,116)=3.05, p=.08)$. Majority members who were exposed to supported minorities changed their position toward the minority position in both the consensus ( $\mathrm{M}=$ -4.44 ) and the nonconsensus ( $M=-0.322$ ) conditions. Majority members exposed to single minorities changed in the direction of the minority position only in the nonconsensus condition ( $M=-1.04$ ) and changed away from the minority position in the consensus condition $(\mathrm{M}=1.73)$.

Similar analyses were carried out on the attitude change data for minority members within groups. There were no significant main effects or interactionsfor any of the variables. Given the very small cell sizes, it is unlikely that we had the power necessary to detect differences if they existed.

\section{Analysis of discussion content}

The audiotaped conversations were analyzed for religious content by several coders working independently (each conversation was analyzed by two coders). Religious comments could be pro-death penalty (e.g. the Bible says an eye for an eye), against the death penalty (e.g. the Bible says thou shalt not kill), or neutral regarding the death penalty(e.g. I wish I could ask my Pastor what he thinks about this issue). Discrepancies in the coders' original judgments were discussed by them until consensus was reached (correlations for each pair of coders ranged from .74 to .91 , all values significant at $p<.01$ ). The total number of religious statements made during discussion were submitted to a 2 (minority in favor of/ against the death penalty) $\times 2$ (consensus/nonconsensus seeking group) analysis of variance. There was a marginal main effect for minority influence type $(F(1,33)=3.79, p=$ $.06)$. Religion was mentioned more frequently in groups where the minority was arguing in favor of the Zeitgeist ( $M=4.07$ ) than in groups where the minority was arguing again st the Zeitgeist ( $M=1.85$ ). This difference makes sense when one considers that the majority members, who were greater in number, could use religion to argue against the pro-death penalty minority. There was a main effect for consensus condition $(F(1,33)=6.97 p=.01)$, with those who were asked to reach consensus mentioning religion more frequently ( $M=4.00$ ) than those who were asked to discuss the issue ( $M=1.37$ ). The relationship between attitude change and the number of religious statements made during discussion was assessed. A significant correlation between majority members' attitude change and the mention of religion was found when the minority argued against the death penalty $(r(67)=-.299, p=.05)$. That is, the more frequently religion was mentioned the more majority members shifted their attitudes toward the position advocated by the minority member. The correlation between attitude change and the number of religious statements made during discussion was not significant for majority members exposed to a minority arguing in favor of the death penalty $(r(43)=.14)$.

\section{Majority members' thought listing}

The thought-listing data were also analyzed for religious content by two independent coders. The inter-observer reliability (percent agreement) across the entire data set was 97 percent. These data allow us to gauge the extent to which religion was on the minds of those who were exposed to a minority source of influence arguing against the death penalty. It is for this reason that we compared the thought-listing data of majority members who were exposed to a minority arguing against the Zeitgeist to the thought listing data of majority members in favor of the death penalty who were not exposed to social influence (i.e. the individual participants in our study). A one-way analysis of variance revealed that majority members who were exposed to a minority source of influence arguing against the death penalty Zeitgeist generated more arguments that were religious in nature $(M=0.80)$ than those who were not exposed to minority influence $(M=0.42$ ) $(F(1,101)=6.17, p=.01)$. There were no differences in the number of religious statements in favor of the death penalty listed by each group of subjects $(F(1,101)=.371, p=.54)$. That is, 
majority members in favor of the death penalty exposed to a minority source arguing against the Zeitgeist were no more likely to generate religious thoughts supporting the death penalty $(M=0.36)$ than those who were not exposed to minority influence $(M=0.29)$. Majority members exposed to minority influence were significantly more likely to list thoughts against the death penalty that were religious in nature $(M=0.45)$ than those who were not exposed to minority influence $(M=0.14)(F(1,101)=7.96$, $p=.01)$. Finally, consensus and nonconsensus seeking group members who were exposed to minorities arguing against the death penalty were compared to no influence controls. There were no differences between the three groups with respect to the number of religious arguments in favor of the death penalty that were listed $(F(2,101)=1.08, p=.34)$. There were significant differences between the three groups with respect to the number of religious arguments against the death penalty listed $(F(2,101)$ $=4.95, p=.01$ ). Post hoc analyses (Least Significant Difference) revealed that both consensus and discussion conditions ( $\mathrm{M}=0.35$ and $\mathrm{M}=$ 0.53 , respectively) differed from the no influence condition ( $M=0.14$ ) ( at $p=.09$ and $p=.01$ respectively) but did not differ significantly from one another.

\section{Perceptions of discussion quality}

The majority members' responses to the 10 questions pertaining to discussion quality were factor analyzed using varimax rotation. Three factors accounted for 59 percent of the variance ( see T able 3 for scale statistics and the appendix for the specific items in each scale). The first factor included items that seemed to measure the extent to which the conversation was a pleasant experience, thus forming an 'enjoyment' scale. The second factor appeared to be related to discussion 'thoroughness'. The third factor appeared to tap into how engaged the participant was in the group discussion, forming an 'engagement' scale.

Majority members' scores on each of the three scales were submitted to a 2 (minority in favor of/ against the death penalty) $\times 2$ (consensus/ nonconsensus seeking group) analysis of variance. The only significant effect was a twoway interaction between minority influence type and consensus condition $(F(1,113)=8.623, p=$ .004). Majority members in the consensus seeking condition evaluated their discussions more favorably when they were exposed to a minorityarguing against the Zeitgeist ( $M=7.65$ ) than when they were exposed to a minority arguing in favor of the Zeitgeist ( $M=7.10)$. The opposite was true of majority members in the nonconsensus condition. Majority members evaluated their discussions more favorably when they were exposed to a minority arguing in favor of the Zeitgeist ( $M=7.70$ ) than when the minority was arguing against the Zeitgeist ( $M=6.54$ ).

The analyses of the 'thoroughness' and 'engagement' scales revealed no significant effects for minority influence exposure type or consensus condition.

\section{Perceptions of minority members}

Majority members' responses to the questions designed to assess their perceptions of the minority source of influence were factor analyzed using varimax rotation. When there were two minority members within the group, the average of the two minorities' scores was used in the analysis. Four factors accounted for 64 percent of the variance ( see Table 3 for scale statistics and the appendix for specific scale items). The first factor appeared to be related to the extent to which the minority source of influence was positively evaluated, forming a 'positive evaluation' scale. The second factor appeared to be related to the minority sources' flexibility, forming an 'inflexibility' scale. The third factor appeared to be related to the minority source of influence's 'participation' rate. Finally, the fourth factor appeared to be related to the majoritymember'sperceptions of the minority's attempt to 'influence' them during discussion.

Majority members' ratings of their respective minority group members on each of the four scales were submitted to a 2 (minority in favor/ against the death penalty) $\times 2$ (consensus/ nonconsensus seeking group) analysis of variance. Positive evaluation scores did not differ as a function of the type of minority influence majority members were exposed to or as a 
Table 3. Discussion and minority source perception scales' statistics and correlations with majority member attitude change

\begin{tabular}{|c|c|c|c|c|}
\hline \multirow[b]{2}{*}{ Perceptions of } & \multicolumn{2}{|l|}{ SCALE } & \multicolumn{2}{|c|}{$\begin{array}{l}\text { Correlation between scale and } \\
\text { attitude change minority's } \\
\text { death penalty position }\end{array}$} \\
\hline & $\%$ of variance & $\alpha$ & Against & In favor \\
\hline \multicolumn{5}{|l|}{ Discussion quality } \\
\hline Enjoyment & 31 & .58 & $-.30 *$ & -.14 \\
\hline Thoroughness & 15 & .87 & .02 & -.12 \\
\hline Engagement & 13 & .69 & .03 & -.09 \\
\hline \multicolumn{5}{|l|}{ Minority source } \\
\hline Positive evaluation & 33 & .85 & -.21 & -.19 \\
\hline Inflexibility & 16 & .61 & -.19 & .11 \\
\hline Participation & 8 & .54 & -.07 & .05 \\
\hline Influence & 7 & .48 & -.09 & -.20 \\
\hline
\end{tabular}

* Significant at $p<.05$.

function of consensuscondition. With respect to the inflexibility scale, there were no effects for the type of minority influence majority members were exposed to, but there were marginally significant differences in the majority members' perceptions of the minority's inflexibility in the two consensus conditions. Those who reached a group decision ( $M=5.78$ ) perceived their fellow minority members as being more inflexible than those who simply held a group discussion ( $M=$ 5.15) $(F(1,115)=2.34, p=12)$. Regarding majority members' perceptions of minority members' participation, there was a main effect for type of minority influence $(F(1,114)=5.36, p=.02)$. That is, minority members arguing against the death penalty were perceived by majority members to participate less ( $M=5.18$ ) than minority members arguing in favor of the death penalty $(M=6.00)$. There was also a main effect for consensus condition $(F(1,114)=4.07, p=$ .046). Minorities were perceived to participate at higher rates in consensus seeking conditions ( $M=5.75$ ) than in nonconsensus seeking conditions ( $M=5.24$ ). Finally, there was a two-way interaction between type of minority influence and consensus condition $(F(1,114)=6.58, p=$ .01). Minority members' participation rates, when they were arguing against the death penalty, were perceived by the majority similarly in both the consensus ( $M=5.11$ ) and nonconsensus ( $M=5.26$ ) conditions, whereas the minority members who were arguing in favor of the death penalty were perceived to participate much more in the consensus condition ( $\mathrm{M}=$ 6.49) than in the nonconsensus condition ( $M=$ 5.19). Influence scores differed as a function of the type of minorityinfluence majority members were exposed to $(F(1,114)=4.08, p=.04)$. Minority members arguing against the death penalty were perceived by majority members as more influential $(M=6.74)$ than minority members arguing in favor of the death penalty $(M=6.20)$. Influence scores did not differ as a function of consensus condition. Finally, all discussion quality and perceptions of minority source scales were correlated with attitude change. These correlations are presented in Table 3.

\section{Discussion}

The primary purpose of this study was to broaden our understanding of the Zeitgeist effects found in the minority influence literature through the use of freely interacting groups discussing the death penalty. Although past research findings consistently support the notion that minorities are at a distinct advantage 
when they argue in favor of the Zeitgeist (Clark \& Maass, 1988a, 1988b, 1990; Paicheler, 1976, 1977), our results are inconsistent with those findings. In our study, within the consensus seeking condition, minorities who argued against the Zeitgeist were more influential than those who argued in favor of capital punishment. Although attitude change data alone cannot explain why minorities arguing against the Zeitgeist were more influential than those who argued in favor of the death penalty, our data do challenge the generalizability of Clark's (1990) explanation for the consistent asymmetries found in the minority influence literature.

The work of both Mugny and Perez (1991) and Tindale et al. (1996) suggests that when minority sources of influence can link their arguments to some shared superordinate belief system that can be used to validate the minority position they will be influential regardless of whether they are arguing in favor of or against the Zeitgeist. This work led us to predict that minorities arguing against the death penalty would be more influential than those arguing in favor of capital punishment when those who argued against the death penalty Zeitgeist appealed to their fellow group members' shared belief in the Christian religion. We found a significant relationship between majority members' attitude change and the frequency with which religion was mentioned during group discussion in the conditions where the minority was arguing against the death penalty but not when they argued in favor of it. The difference between the two influence conditions makes sense when the pool of religious arguments regarding the death penalty is considered. In our sample, only one argument in favor of the death penalty was mentioned (i.e. the Bible says an eye for an eye) whereas there were several different arguments suggesting that the implementation of the death penal ty was not consonant with the teachings of the Bible (i.e. thou shalt not kill, God should be the final judge of our behavior, criminals will pay for their actions in the afterworld, God can deliver far more severe punishment than humans can, only God can be just). In other words, once group members decided that the issue could be con- sidered on religious grounds, those who were opposed to the death penalty had available to them many more arguments that they could use to support their position than did those arguing in favor of capital punishment. It is important to point out that, consistent with persuasive arguments theory (Vinokur \& Burnstein, 1978), had the pool of religious arguments favoring the death penalty been larger, minorities arguing against the death penalty may not have been as influential because their religious arguments could have been more easily counterargued with religion. For example, we would not predict that minorities arguing against the abortion Zeitgeist (which would be a pro-abortion position within our undergraduate population) would enjoy the same advantage as minorities arguing against the death penalty Zeitgeist simply because many religious arguments could be used against the position they advocated. In other words, the presence of a shared representation (religious identity) coupled with a large argument pool favoring the minority position allowed the minority arguing against the Zeitgeist to exert more influence than the minority arguing against the Zeitgeist. The presence of a shared representation may help to create a context where certain types of arguments are perceived as relevant to the issue at hand. That is, the greater number of religious arguments against the death penalty would have mattered less had our participants not shared strong Christian identities and had not chosen to consider the religious implications of their beliefs regarding capital punishment.

Majority members who were in favor of the death penalty and who were exposed to a minority source of influence arguing against the death penaltyZeitgeist were more likely to list religious thoughts than those who were in favor of the death penal ty who were not exposed to minority influence. Clearly, religious statements, especially religious arguments against the death penalty were much more salient to those exposed to minorities arguing against the death penalty than those who were not exposed to minority influence. These results are consistent with our 'shared religious beliefs' explanation for the attitude change data. That is, they 
suggest that the minority source of influence led majority members to recognize the relevance of religion to the death penalty issue and to consider the religious implications of the position they held.

Although the reviewed literature did not allow for firm a priori predictions regarding the effects of reaching consensus on attitude change to be made, we find the differences between consensus seeking and discussion only conditions to be particularly interesting. Perhaps the need to reach consensus prompted participants to search for and to ultimately find some common ground on which the death penalty could be discussed. In other words, the participants may have concluded that they were unlikely to reach a decision unless such common ground was found. One finding seems to be quite consonant with this interpretation. Religion was mentioned more frequently in the consensus seeking conditions than it was in the discussion only conditions. This suggests that in contexts where a collective decision was not required, group members may not have felt compelled to find a shared way of framing the problem so that it could be discussed and agreement could be reached. The two-way interaction between consensus condition and minority influence type for the discussion enjoyment scale al so suggests that when common ground is found, the experience of discussing the issue becomes more enjoyable.

It is interesting to note that none of the studies exploring Zeitgeist effects have required groups of individuals to discuss an issue with the goal of reaching a collective decision in mind. Without consensus pressure, majority group members may feel more comfortable dismissing minority points of view. That is, an opinion minority can impose her/ his opinion upon the group more easily in consensus seeking versus discussion contexts (Miller \& Anderson, 1979; Miller et al., 1987). Consistent with this notion, we found that minorities were perceived as being more extreme and inflexible and were thought to participate at higher rates in consensus seeking versus discussion contexts.

Future research could explore the extent to which consensus pressure leads group members to seek out common ground on which they can discuss the issue at hand and the process by which this common ground is found. It may be that the impact of shared representations is most pronounced in consensus seeking contexts. O ur results are limited in the extent to which they can offer unequivocal support for the notion that consensus pressure prompts group members to find a common frame of reference or task relevant shared representation to assist them in reaching agreement among themselves. However, they do suggest that, at least in some contexts, minorities arguing against the Zeitgeist can be more influential than those arguing in favor of it. They also provide provisional support for the notion that minorities arguing against the Zeitgeist are especially influential when their arguments appeal to a shared belief system within the group.

\section{Notes}

1. These pilot data were collected in 1994. At that time, roughly 70 percent of the subject pool at Grand Valley State University were in favor of the death penalty. Given that our data were collected over a four year period, it seemed prudent to assess whether or not the 'Zeitgeist' changed within our student population during that time. Data collected in 1995- 6 from our first 30 groups (first 150 participants) reveal that 71 percent of the individuals were in favor of the death penalty. Data collected in 1997-8 from our last 30 groups show that 73 percent of the subjects were in favor of the death penalty. Similarly, national opinion polls taken between 1972 and 1996 show a steady increase in the number of Americans in favor of the death penalty with this pattern holding for both males and females and both Blacks and Whites (Davis \& Smith, 1996). In 1995, three out of four Americans were in favor of the use of capital punishment in some contexts.

2. It is important to point out that these data were collected within the context of a larger ongoing study exploring minority influence. The larger ongoing study was designed to explore the effects of reaching consensus on minority influence potency and the minority's ability to inspire divergent thinking. In our laboratory we collect from groups even when their composition does 
not match our experimental design. It is for this reason that after several years of data collection we had approximately an equal number of groups where minority members were arguing against and in favor of the Zeitgeist. Given the distribution of opinions regarding the death penalty in the Grand Valley State U niversity subject pool, the majority of those who came to our lab were in favor of the death penalty. Only 21 percent of the 75 five-person groups had compositions where the true minority position (being against the death penalty) was held by the majority (at least three) of the group members. The data from all 16 of these groups are reported in this paper. The comparison groups (where the actual minority opinion is held by the majority of the group members) were randomly chosen from the remaining 59 groups.

\section{Acknowledgments}

Preparation of this article was supported by NSF Grant \#SBR-9730822 awarded to the first author and R. Scott Tindale. We would like to thank Anne Maass and three anonymous reviewers for their helpful comments on an earlier draft of this paper. Portions of this paper were presented at the $1998 \mathrm{Nags} \mathrm{H}$ ead International Conference on Groups, Networks, and Organizations, Highland Beach, FL and at the 1998 meetings of the Midwestern Psychological Association, Chicago, IL.

\section{References}

Berkowitz, L., \& H oward, R. C. (1959). Reactions to opinion deviates as affected by affiliation need $(n)$ and group member interdependence. Sociometry, 22, 81-91.

Clark, R. D., III (1988). On predicting minority influence. European Journal of Social Psychology, 18, 515-526.

Clark, R. D., III (1990). Minority influence: The role of argument refutation of the majority position and social support for the minority. European Journal of Social Psychology, 20, 489-497.

Clark, R. D., III (1995). On being excommunicated from the European view of minority influence: $A$ reply to Perez et al. European Journal of Social Psychology, 25, 711-714.

Clark, R. D., III, \& Maass, A. (1988a). Social categorization in minority influence: The case of homosexuality. European Journal of Social Psychology, 18, 347-364.
Clark, R. D., III, \& M aass, A. (1988b). The role of social categorization and perceived source credibility in minority influence. European Journal of Social Psychology, 18, 381-394.

Clark, R. D., III, \& Maass, A. (1990). The effects of majority size on minority influence. European Journal of Social Psychology, 20, 119-132.

Davis, J. A., \& Smith, T. W. (1996). General social surveys 1972-1996 [M achine-readable data file]. Chicago, IL: National O pinion Research Center (Producer). Storrs, CT: Roper Public O pinion Research Center (Distributor).

Davis, J. H ., Kerr, N. L., Stasser, G., M eek, D., \& H olt, R. (1977). Victim consequences, sentence severity, and decision processes in mock juries. Organizational Behavior and $\mathrm{H}$ uman Performance, 18, 346-365.

Festinger, L. (1950). Informal social communication. Psychological Review, 57, 217-282.

Festinger, L. (1954) . A theory of social comparison processes. H uman Relations, 7, 117-140.

Jones, E. E., \& deCharms, R. (1957). Changes in social perception as a function of the personal relevance of behavior. Sociometry, 20,75-85.

Kerr, N. L., \& MacCoun, R. J. (1985). The effects of jury size and polling method on the process and product of jury deliberation. Journal of Personality and Social Psychology, 48, 349-363.

Kruglanski, A. W., \& Mackie, M. (1990). Majority and minority influence: A judgmental process analysis. European Review of Social Psychology, 1, 229-261.

Levine, J. M. (1980). Reaction to opinion deviance in small groups. In P. Paulus (Ed.), Psychology of group influence (pp. 187-231). Hillsdale, NJ: Erlbaum.

Levine, J. M., \& Russo, E. M. (1987). Majority and minority influence. In C. Hendrick (Ed.), Group processes. Newbury Park, CA: Sage.

Maass, A., \& Clark, R. D., III (1984). The hidden impact of minorities: Fifteen years of minority influence research. Psychological Bulletin, 95, 428-450.

Maass, A., Clark, R. D., III, \& H aberkorn, G. (1982). The effects of differential ascribed category membership and norms on minority influence. European Journal of Social Psychology, 12, 89-104.

Miller, C. E., \& Anderson, P. D. (1979). Group decision rules and the rejection of deviates. Social Psychology Quarterly, 42, 354-363.

Miller, C. E., Jackson, P., Mueller, J., \& Schersching, C. (1987). Some social psychological effects of group decision rules. Journal of Personality and Social Psychology, 52, 325-332.

Moscovici, S. (1976). Social influence and social change. London: Academic Press. 
Moscovici, S., Lage, E., \& Naffrechoux, M. (1969). Influence of a consistent minority on the responses of a majority in a color perception task. Sociometry, 32, 365-379.

Mugny, G., \& Perez, J. A. (1991). The social psychology of minority influence. Cambridge: Cambridge University Press.

Nemeth, C. (1977). Interactions between jurors as a function of majority vs. unanimity decision rules. Journal of A pplied Social Psychology, 7, 38-56.

Nemeth, C. (1986). Differential contributions of majority and minority influence. Psychological Review, 93, 23-32.

Paicheler, G. (1976). Norms and attitude change: I. Polarization and styles of behavior. European Journal of Social Psychology, 6, 405-427.

Paicheler, G. (1977). Polarization of attitudes in homogeneous and heterogeneous groups. European Journal of Social Psychology, 9, 85-96.

Perez, J. A., Papastamou, S., \& Mugny, G. (1995). 'Zeitgeist' and minority influence: Where is the causality? European Journal of Social Psychology, 25, 703-710.

Rose, R. (1954). T welve angry men. Chicago: Dramatic Publishing.

Smith, C. M., Tindale, R. S., \& Anderson, E. M. (in press) The impact of shared representations on minority influence in freely interacting groups. In C. de Dreu \& N. de Vries (Eds.), Group consensus and innovation: Fundamental and applied perspectives. Oxford: Blackwell.

Smith, C. M., Tindale, R. S., \& Dugoni, B. L. (1996). $M$ inority and majority influence in freely interacting groups: Qualitative versus quantitative differences. British Journal of Social Psychology, 35, 137-149.

Smith, C. M., Tindale, R. S., \& Steiner, L. (1998). Investment decisions by individuals and groups in 'sunk cost' situations: The potential impact of shared representations. Group Processes \& Intergroup Relations, 1, 175-189.

Tindale, R. S., Davis, J. H., Vollrath, D. A., Nagao, D. H., \& Hinsz, V. B. (1990a). Asymmetrical social influence in freely interacting groups: A test of three models. Journal of Personality and Social Psychology, 58, 438-449.

Tindale, R. S., Filkins, J., Thomas, L. S., \& Smith, C. M. (1993). An attempt to reduce conjunction errors in decision-making groups. Paper presented at the Society for Judgment and Decision Making meeting, Washington, DC, November.
Tindale, R. S., Sheffey, S., \& Filkins, J. (1990b). Conjunction errors by individuals and groups. Paper presented at the Society for Judgment and Decision Making M eeting, New O rleans, November.

Tindale, R. S., Smith, C. M., Thomas, L. S., Filkins, J., $\&$ Sheffey, S. (1996). Shared representations and asymmetric social influence processes in small groups. In E. Witte \& J. Davis (Eds.) , Understanding group behavior: Consensual action by small groups (Vol. 1, pp. 81-103). Mahwah, NJ: Erlbaum.

Vinokur, A., \& Burnstein, E. (1978). Depolarization of attitudes in groups. Journal of Personality and Social Psychology, 36, 872-885.

Wood, W., Lundgren, S., O uellette, A., Busceme, S., $\&$ Blackstone, T. (1994). Minority influence: A meta-analytic review of social influence processes. Psychological Bulletin, 115, 323-345.

Paper received $22 \mathrm{M}$ arch 1999; revised version accepted 4 M ay 2000

\section{Biographical notes}

CHRISTINE M. SMITH is an associate professor of psychology at Grand Valley State University. Her research focuses upon minority influence in freely interacting discussion groups and individual versus group decision making.

AMANDA DYKEMA-ENGBLADE is a graduate student in the Applied Social Psychology Program at Loyola University, Chicago. Her research interests include transactive memory and minority influence.

ANGELA WALKER is a graduate student at the University of Connecticut. Her research interests include power dynamics in communal relationships, subtle forms of racism and sexism, stigma, and group dynamics.

TAMMI S. NIVEN is a graduate student in the Law/ Psychology Program at the U niversity of Nebraska. Her research interests include jury and juror decision making, juror's weighting of conflicting expert testimony, and the death penalty.

THOMAS MCGOUGH earned his bachelor's degree in psychology from Grand Valley State U niversity. 


\section{Appendix}

Items for Minority Source and Discussion Perception Scales

Discussion quality

Enjoyment

I enjoyed discussing the issue.

It was easy to defend my side of the issue.

I never felt uncomfortable during discussion.

Thoroughness

Our discussion was ver y thorough.

We really examined the issue.

Engagement

I was relieved when the discussion was over (reverse scored).

Time seemed to pass quickly during our discussion.

M inority source

Positive evaluation

Seemed intelligent.

Presented logical arguments about the issue.

Made our discussion more enjoyable.

Appears to be knowledgeable regarding the death penalty.

Made our discussion more stimulating.

Seems to be a very friendly person.

Inflexibility

Seemed very rigid in their death penalty opinion.

Seemed very extreme in their death penalty position.

Participation

Dominated the entire conversation.

Did not talk much at all (reverse scored).

Influence

Was very influential during discussion.

Is not the kind of person to go along just to fit in.

Was very fair during our discussion. 